\title{
Effects of strontium ranelate on wear particle-induced aseptic loosening in female ovariectomized mice
}

\author{
TIANXIANG GENG $^{1 *}$, XI CHEN $^{1 *}$, MENGXUE ZHENG $^{1}$, HAOCHEN YU $^{1,2}$, \\ SHUAI ZHANG ${ }^{3}$, SHOUXUAN SUN ${ }^{3}$, HAOHUI GUO ${ }^{3}$ and QUNHUA JIN ${ }^{3}$ \\ ${ }^{1}$ Department of Orthopedic Surgery, Ningxia Medical University, Yinchuan, Ningxia Hui Autonomous Region 750004; \\ ${ }^{2}$ Biotechnology Laboratory, School of Basic Medicine, Mudanjiang Medical University, Mudanjiang, Heilongjiang 157000; \\ ${ }^{3}$ Department of Orthopedic Surgery, General Hospital of Ningxia Medical University, \\ Yinchuan, Ningxia Hui Autonomous Region 750004, P.R. China
}

Received December 30, 2017; Accepted May 2, 2018

DOI: $10.3892 / \mathrm{mmr} .2018 .9133$

\begin{abstract}
Aseptic loosening and menopause-induced osteoporosis are caused by an imbalance between bone formation and osteolysis. With an aging population, the probability of simultaneous occurrence of such conditions in an elderly individual is increasing. Strontium ranelate (SR) is an anti-osteoporosis drug that promotes bone formation and inhibits osteolysis. The present study compared the effects of SR with those of the traditional anti-osteoporosis drug alendronate (ALN) using an ovariectomized mouse model of osteolysis. The degree of firmness of the prosthesis and the surrounding tissue was examined, a micro-CT scan of the prosthesis and the surrounding tissue was performed, and the levels of inflammatory and osteogenic and osteoclast factors were examined. It was observed that treatment with SR and ALN improved the bond between the prosthesis and the surrounding bone tissue by reducing the degree of osteolysis, thus improving the quality of bone around the prosthesis. SR increased the secretion of osteocalcin, runt-related transcription factor 2 and osteoprotegerin (OPG). It additionally decreased the expression of the receptor activator of nuclear factor- $\kappa \mathrm{B}$ ligand (RANKL) and consequently increased the
\end{abstract}

Correspondence to: Dr Qunhua Jin, Department of Orthopedic Surgery, General Hospital of Ningxia Medical University, 804 Shengli Street, Yinchuan, Ningxia Hui Autonomous Region 750004, P.R. China

E-mail: jinqunhua@sina.com

${ }^{*}$ Contributed equally

Abbreviations: ALN, alendronate; BV, bone volume; BS/BV, bone surface/bone volume ratio; BV/TV, bone volume fraction; $\mathrm{OPG}$, osteoprotegerin; RANKL, receptor activator of nuclear factor- $\kappa \mathrm{B}$ ligand; SR, strontium ranelate; Tb.N, trabecular number; Tb.Th, trabecular thickness

Key words: SR, ALN, aseptic loosening, ovariectomy, bone formation, bone resorption protein ratio OPG/RANKL, whereas ALN exhibited the opposite effect. Furthermore, SR and ALN suppressed tumor necrosis factor- $\alpha$ and interleukin- $1 \beta$ production, with SR exerting a more marked effect. The present results demonstrate that SR and ALN may stimulate bone formation and inhibit bone resorption in the ovariectomized mouse model of wear particle-mediated osteolysis, with SR demonstrating better effects compared with ALN.

\section{Introduction}

Wear particle-induced aseptic loosening has become one of the most important causes of arthroplasty failure, and results in high healthcare costs and complex revision procedures (1). Wear particles are the debris from joint replacement implants that may induce inflammation and bone resorption at the interface between the surface of a prosthesis and its adjoining bone (2). These debris particles stimulate the secretion of various proinflammatory cytokines, including tumor necrosis factor- $\alpha$ (TNF- $\alpha$ ), interleukin (IL)-1 and IL-6 (3). Studies have demonstrated that TNF- $\alpha$, receptor activator of nuclear factor $-\kappa \mathrm{B}(\mathrm{NF}-\kappa \mathrm{B})$ ligand (RANKL) and IL-8 are present in the serum of patients with aseptic loosening $(4,5)$. At the bone-implant interface, activated macrophages, multinucleated giant cells, osteoclasts and fibroblasts are detected on the interface membranes (6). Macrophage recruitment and activation increase the concentration of local pro-inflammatory factors and ultimately lead to inflammation-induced osteoclastogenesis (4). Regulation of the release of osteoblast cytokines, including osteoprotegerin (OPG) and RANKL, is another mechanism of wear particle-induced osteolysis (7). Therefore, the OPG-RANKL-RANK axis has an important role in the pathophysiological process of aseptic loosening (8). RANK is primarily expressed on the plasma membrane of osteoclasts. RANKL activates the $\mathrm{NF}-\kappa \mathrm{B}$ signaling pathway and subsequently induces differentiation of osteoclasts and inhibits apoptosis by binding to its specific receptor, RANK (9). OPG, which is secreted by numerous cells, including osteoblasts and mesenchymal stem cells, is a soluble competitive decoy receptor for RANK and inhibits the NF- $\kappa$ B signaling pathway by decreasing the binding of RANKL to 
RANK (10). In other words, it inhibits the differentiation and activation of osteoclasts, and induces their apoptosis. In the regulation of bone metabolism, it is essential for the levels of OPG and RANKL to be balanced. Therefore, osteolysis is one of the most intricate complications prosthetic joint replacements and influences the long-term functional recovery of patients.

The loss of estrogen is one of the physiological characteristics of female menopause and mediates primary osteoporosis, which is characterized by a reduction in bone density and damage to bone structure (11). In the first few years of menopause, the rapid decline of estrogen levels in women leads to an increase in bone remodeling, which is manifested as increased bone formation and bone resorption. However, the original balance of bone metabolism later alters; bone resorption surpasses bone formation, resulting in bone loss and eventually osteoporosis (12-14). Estrogen deficiency during menopause has a direct effect on the differentiation and activity of osteoblasts and osteoclasts, and it additionally increases the secretion of inflammatory cytokines, which may increase the activity of osteoclasts and reduce their apoptosis $(15,16)$. With the advancement of medical technology, numerous chronic diseases are effectively treated. Humans have a longer lifespan, however, consequently face the complications of osteoporosis and possible total joint replacement due to aging (17). A previous study demonstrated that the cortical bone of patients with osteoporosis is markedly thinner compared with a healthy individual, particularly in the medial, lateral and posterior parts of the bone (18). An osteoporotic bone (particularly the medial and posterior parts) lacks a complete structure and the intramedullary canal is wider compared with a normal bone. These factors will slow bone growth in the direction of the implant following joint replacement, thereby increasing the risk of aseptic loosening (19). In certain patients with severe osteoporosis, the surgical treatment must be postponed until enough bone mass has been restored (20). Diphosphate is a drug that controls osteoporosis and inhibits osteoclast-mediated bone resorption (21). A previous study demonstrated that bisphosphonates may increase bone mass in patients with osteoporosis and delay the development of the disease (22). Another study revealed that bisphosphonates reduce bone resorption at the bone-implant interface and may prevent aseptic loosening following an arthroplasty (23).

Strontium ranelate (SR), developed by Servier Laboratories (Neuilly-sur-Seine, France), has been demonstrated to be effective anti-osteoporosis therapeutic, and has the potential to reduce the incidence of spinal and hip fracture in postmenopausal women (24). SR has been examined in numerous studies, which have verified its distinct effects on bone metabolism. It has been reported to increase bone mass and to suppress the activity of osteoclasts, thus preventing bone loss (25). In another previous study, SR has been observed to stimulate bone collagen synthesis and to decrease the expression of functional osteoclast markers, including carbonic anhydrase II and vitronectin receptor (26).

In the present study, an ovariectomized mouse model of long-term aseptic loosening was used to compare the effects of SR with those of the traditional anti-osteoporosis drug alendronate $(\mathrm{ALN})$ on aseptic loosening under the conditions of osteoporosis with estrogen deficiency.

\section{Materials and methods}

Wear particle preparation. Unmixed titanium particles (Zimmer Biomet, Warsaw, IN, USA; $\sim \mu \mathrm{m}$ ) were used in the present study. Prior to injection, the particles were rinsed in $70 \%$ ethanol for $48 \mathrm{~h}$ at room temperature, washed twice in phosphate-buffered saline, and subsequently autoclaved at $180^{\circ} \mathrm{C}$ for $6 \mathrm{~h}$ to remove any endotoxins. A commercial detection kit (E-Toxate ${ }^{\mathrm{TM}}$; Sigma-Aldrich; Merck KGaA, Darmstadt, Germany) was used to test whether the treated wear debris contained endotoxins (27).

Animals. In the present study, 40 female C57BL/6j mice (18 months-old; Experimental Animal Center of Ningxia Medical University, Yinchuan, China) were used, each weighing $26 \pm 2 \mathrm{~g}$. All the mice were housed in mechanically ventilated cages ( $4-5$ mice per cage) and maintained at $25^{\circ} \mathrm{C}$ constant temperature, constant pressure, and on a $12 / 12 \mathrm{~h}$ light/dark cycle, with ad libitum access to water and food. The experimental protocol was conducted in accordance with the National Institutes of Health guidelines for the care and use of laboratory animals (28) and was approved by the Ethics Committee of the General Hospital of Ningxia Medical University (Yinchuan, China).

Experimental groups and treatments. The mice were randomly subdivided into four groups (10 mice per group): Sham group; control group; SR group; and ALN group. Ovariectomy or sham surgery was performed on the mice at 18 months of age. At 3 months after the induction of osteoporosis, all the mice were subjected to joint prosthesis implantation into the right lower extremity under general anesthesia induced by intraperitoneal injection of Nembutal $(0.6 \%$ pentobarbital sodium, NeoBioscience Technology Co., Ltd., Shenzhen, China). All the experimental methods were conducted as described previously (29). In an aseptic environment, the tibial plateau was exposed through the medial parapatellar approach, and one titanium pin was implanted gently into the proximal tibia so that the head of the pin was kept in the same plane as the surface of the tibial plateau. The cut was washed with normal saline containing $100 \mathrm{U} / \mathrm{ml}$ penicillin and $100 \mu \mathrm{g} / \mathrm{ml}$ streptomycin, and each layer was closed separately with absorbable string sutures. Prior to insertion of the titanium nails during the surgical procedure, the tibia canal was injected with $10 \mu \mathrm{l}$ titanium suspension $\left(4 \times 10^{4}\right.$ particles of titanium in normal saline). This action was followed by further $20 \mu$ injections of particles into the joint capsule every 2 weeks following the operation, until the end of the experiment. Following 1 week of adaptive feeding, the SR group was orally administered SR (Protelos ${ }^{\circledR}$; Servier Laboratories; cat. no. S12911-2) at $625 \mathrm{mg} / \mathrm{kg} /$ day for 7 days per week. The ALN group received ALN (Fosamax Plus; Merck \& Co., Inc., Whitehouse Station, NJ, USA) orally at $1 \mathrm{mg} / \mathrm{kg}^{\prime}$ day for 7 days per week $(30,31)$. The animals were euthanized by carbon dioxide asphyxiation at 12 weeks following treatment with the drug.

Titanium prosthesis steadiness examined by a pullout test. Following euthanasia, the tibia with the titanium nail was removed from the body of each mouse. To expose the head of the titanium implant, all muscles and tissues around the 


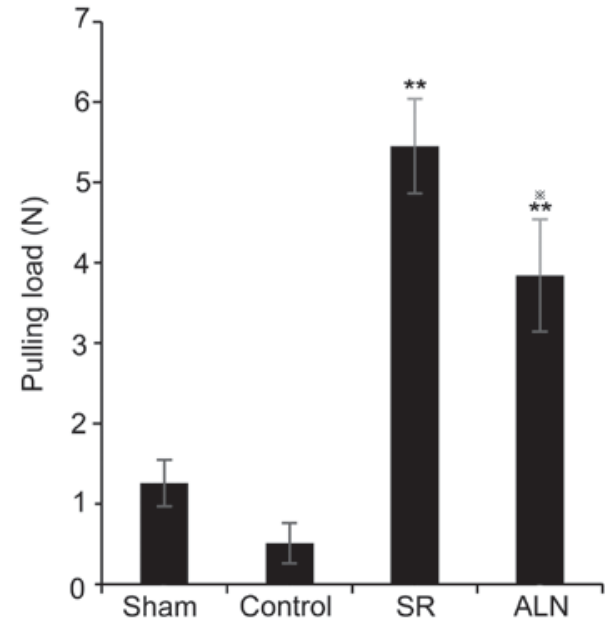

Figure 1. Pullout test for estimation of the bone-bonding capacity of the titanium pin implants. $\mathrm{n}=5$ mice/group. ${ }^{* *} \mathrm{P}<0.01$ vs. control; ${ }^{*} \mathrm{P}<0.05$ vs. SR. $\mathrm{SR}$, strontium ranelate; ALN, alendronate.

bone were carefully removed. Each bone was fixed with dental cement onto a special clamp, which was designed to align the long axis of the implants with the long axis of the HP-100 Control electronic universal testing machine (Yueqing Zhejiang Instrument Scientific Co., Ltd., Zhejiang, China). With the mouse limb and the custom fixture properly positioned, the HP-100 device pulled the pin out of the tibia at a rate of $2 \mathrm{~mm} / \mathrm{min}$. The load values were registered automatically by software (Edburg 1.0; Yueqing Zhejiang Scientific Instrument Co., Ltd.).

Micro-computed tomography (CT) scans. The tibias (with all soft tissues removed) from four mice in each group were fixed in $4 \%$ paraformaldehyde at $4^{\circ} \mathrm{C}$ for 4 weeks for scanning by micro-CT in a SkyScan 1176 scanner (Bruker microCT, Kontich, Belgium) at a resolution of $9 \mu \mathrm{m}$. The micro-CT scans were acquired at $900 \mathrm{~ms}$ exposure time, $45 \mathrm{~kW}$ voltage and $550 \mathrm{~mA}$ current. Auto data analysis software (NRecon ver. 1.1.11; Bruker microCT) was used to reconstruct and acquire images from the micro-CT analyses and to evaluate the bone volume fraction (BV/TV), trabecular thickness (Tb.Th), trabecular number (Tb.N), bone volume (BV) and bone surface/bone volume ratio (BS/BV) of the shinbone surrounding the titanium nail. The structure model index (SMI) is a method intended for determining the plate- or rod-like geometry of trabecular structures. It uses the alteration in surface area (BS, from Isosurface) as volume increases infinitesimally to calculate $\mathrm{SMI}=0$ for plates, 3 for rods and 4 for solid spheres (32).

ELISA. This assay was performed to detect the IL-1 $\beta$ and TNF- $\alpha$ protein expression levels in mouse serum. The quantitative analysis was performed using mouse-specific ELISA kits (TNF- $\alpha$; cat. no. EMC102a.96; and IL-1 $\beta$; cat. no. EMC001b.96; NeoBioscience Technology, Co., Ltd., Shenzhen, China), and the assay was performed, according to the manufacturer's protocol.

Western blot analysis. The tissue surrounding the implant was frozen in liquid nitrogen and ground with a chilled mortar and pestle. Radioimmunoprecipitation assay buffer with $1 \mathrm{mM}$ phenylmethylsulfonyl fluoride (Nanjing KeyGen Biotech Co., Ltd., Nanjing, China) was used to lyse the tissue. The protein concentration was measured with a bicinchoninic assay kit (Nanjing KeyGen Biotech Co.,Ltd.). Subsequently, $30 \mu$ g protein mixed with $5 \mathrm{X}$ loading buffer was separated by Tris-glycine SDS-PAGE on a $12 \%$ gel and transferred to polyvinylidene difluoride membranes (EMD Millipore, Billerica, MA, USA). The membranes were incubated for $1 \mathrm{~h}$ at room temperature in Tris-buffered saline with $0.5 \%$ Tween-20 (TBST) containing $5 \%$ nonfat dry milk, and subsequently incubated overnight at $4^{\circ} \mathrm{C}$ with the following primary antibodies: Anti-osteocalcin (OCN; cat. no. ab93876; 1:1,000), anti-runt-related transcription factor 2 (Runx2; cat. no. ab23981; 1:1,000), anti-OPG (cat. no. ab183910; 1:1,000), anti-RANKL (cat. no. ab9957; 1:1,000; all Abcam, Cambridge, UK), anti- $\beta$-actin (cat. no. 4970; 1:1,000, Cell Signaling Technology, Inc., Danvers, MA, USA) or anti-GAPDH (cat. no. 2118; 1:1,000, Cell Signaling Technology, Inc.). Membranes were washed three times with TBST and incubated for $1 \mathrm{~h}$ at room temperature with the horseradish peroxidase-tagged secondary antibody (cat. no. PAB160009; 1:5,000; OriGene Technologies, Inc., Beijing, China). The Enhanced Chemiluminescent Western Blotting Detection Reagent (Nanjing KeyGen Biotech Co., Ltd.) was used to test the bands. Quantity One software (Ver. 4.6.7; Bio-Rad Laboratories, Inc., Hercules, CA, USA) served for semi quantitative analysis.

Statistical analysis. The data are presented as the mean \pm standard deviation. Each experiment was repeated three times. Differences among the groups were evaluated by one-way analysis of variance (ANOVA). The least-significant difference post hoc test was conducted to distinguish the means between different groups. SPSS 19.0 (IBM Corp., Armonk, NY, USA) served as the analysis software. $\mathrm{P}<0.05$ was considered to indicate a significant difference.

\section{Results}

Pullout test. The special clamp was powerful enough to hold the titanium nail during the entire pullout test. The average pulling load was $0.51 \pm 0.25 \mathrm{~N}$ in the control group and $1.26 \pm 0.29 \mathrm{~N}$ in the sham group (Fig. 1). There was a significant difference in the pulling force between the SR group $(5.45 \pm 0.59 \mathrm{~N})$ and the ALN group $(3.84 \pm 0.7 \mathrm{~N})$, the results of one-way ANOVA demonstrated that there was a significant difference between the SR group and the ALN group $(\mathrm{P}<0.05)$. Additionally, the pulling force in the SR group and ALN group was significantly increased compared with the control groups (Fig. $1 ; \mathrm{P}<0.01$ ).

Micro-CT imaging analysis. The micro-CT scans demonstrated marked distinctions in the bone microstructure among the four groups of mice. In Fig. 2, although certain parts of the surrounding bone are hidden in the shadow of the titanium pin, osteolysis around the pin is still observed, being the most severe in the control group.

Data on the Tb.Th, Tb.N, BS/BV ratio, structure model index (SMI), trabecular pattern factor (Tb.Pf) and BV/TV were obtained from the micro-CT analysis of a region of 
interest. The treatment of mice with SR and ALN increased the BV/TV in the two drug-treated groups compared with the sham and control groups (Fig. $3 \mathrm{~A} ; \mathrm{P}<0.05 ; 15.70 \pm 0.67 \%$ in the sham group, $14.53 \pm 0.89 \%$ in the control group, $19.50 \pm 0.55 \%$ in the SR group and $17.63 \pm 0.84 \%$ in the ALN group); the results of one-way ANOVA demonstrated that there was a significant difference between the SR group and the ALN group $(\mathrm{P}<0.05)$. The $\mathrm{BS} / \mathrm{BV}$ ratio significantly decreased in the SR and ALN groups compared with the sham and control groups (Fig. 3B; $\mathrm{P}<0.05 ; 51.76 \pm 1.841 / \mathrm{mm}$ in the sham group, $56.69 \pm 1.091 / \mathrm{mm}$ in the control group, $45.33 \pm 1.801 / \mathrm{mm}$ in the SR group and $47.58 \pm 1.391 / \mathrm{mm}$ in the ALN group); the results of one-way ANOVA demonstrated that there was no significant difference between the SR group and the ALN group ( $\mathrm{P}>0.05)$. Additionally, the SMI significantly decreased in the two drug-treated groups compared with the sham and control groups (Fig. 3C; $\mathrm{P}<0.01 ; 0.30 \pm 0.010$ in the sham group, $0.37 \pm 0.011$ in the control group, $0.24 \pm 0.008$ in the SR group, and $0.26 \pm 0.007$ in the ALN group); the results of one-way ANOVA demonstrated that there was a significant difference between the SR group and the ALN group $(\mathrm{P}<0.01)$. However, the Tb.Th significantly increased in the drug-treated groups compared with the sham and control groups (Fig. 3D; $\mathrm{P}<0.01 ; 0.05 \pm 0.001 \mathrm{~mm}$ in the sham group, $0.05 \pm 0.001 \mathrm{~mm}$ in the control group, $0.06 \pm 0.001 \mathrm{~mm}$ in the SR group and $0.06 \pm 0.001 \mathrm{~mm}$ in the ALN group), and the results of one-way ANOVA demonstrated that there was a significant difference between the SR group and the ALN group $(\mathrm{P}<0.01)$, as did the Tb.N (Fig. 3E; $\mathrm{P}<0.05 ; 2.57 \pm 0.131 / \mathrm{mm}$ in the sham group, $2.25 \pm 0.241 / \mathrm{mm}$ in the control group, $3.44 \pm 0.171 / \mathrm{mm}$ in the SR group and $2.94 \pm 0.171 / \mathrm{mm}$ in the ALN group); the results of one-way ANOVA demonstrated that there was a significant difference between the SR group and the ALN group $(\mathrm{P}<0.05)$. Tb.Pf significantly decreased in the SR and ALN groups compared with the other two groups (Fig. 3F; $\mathrm{P}<0.01$; $1.34 \pm 0.051 / \mathrm{mm}$ in the sham group, $1.61 \pm 0.081 / \mathrm{mm}$ in the control group, $0.72 \pm 0.041 / \mathrm{mm}$ in the SR group and $0.77 \pm 0.06$ $1 / \mathrm{mm}$ in the ALN group); the results of one-way ANOVA demonstrated that there was no significant difference between the SR group and the ALN group $(\mathrm{P}>0.05)$.

ELISA results. The serum expression levels of TNF- $\alpha$ in the SR and ALN groups were significantly decreased compared with the sham and control groups (Fig. 4; $\mathrm{P}<0.01 ; 618 \pm 7 \mathrm{pg} / \mathrm{ml}$ in the sham group, $701 \pm 11 \mathrm{pg} / \mathrm{ml}$ in the control group, $327 \pm 9 \mathrm{pg} / \mathrm{ml}$ in the SR group and $394 \pm 6 \mathrm{pg} / \mathrm{ml}$ in the ALN group). Similarly, the expression level of IL-1 $\beta$ was significantly decreased in the two drug-treated groups compared with the sham and control groups (Fig. 4; $\mathrm{P}<0.01 ; 746 \pm 18 \mathrm{pg} / \mathrm{ml}$ in the sham group, $830 \pm 22 \mathrm{pg} / \mathrm{ml}$ in the control group, $421 \pm 4 \mathrm{pg} / \mathrm{ml}$ in the SR group and $482 \pm 7 \mathrm{pg} / \mathrm{ml}$ in the ALN group).

Western blot analysis. Western blotting was conducted to assess the expression levels of the osteoblast markers Runx2 and OCN, and the osteoblast cytokines OPG and RANKL (Fig. 5). The expression levels of Runx 2 and OCN in the SR and ALN groups were significantly higher compared with the sham and control groups (Fig. 5; $\mathrm{P}<0.01$; Runx 2, $0.34 \pm 0.008$ in the sham group, $0.05 \pm 0.005$ in the control group, $0.52 \pm 0.007$ in the ALN group, and 1.02 \pm 0.019 in the SR group; the results
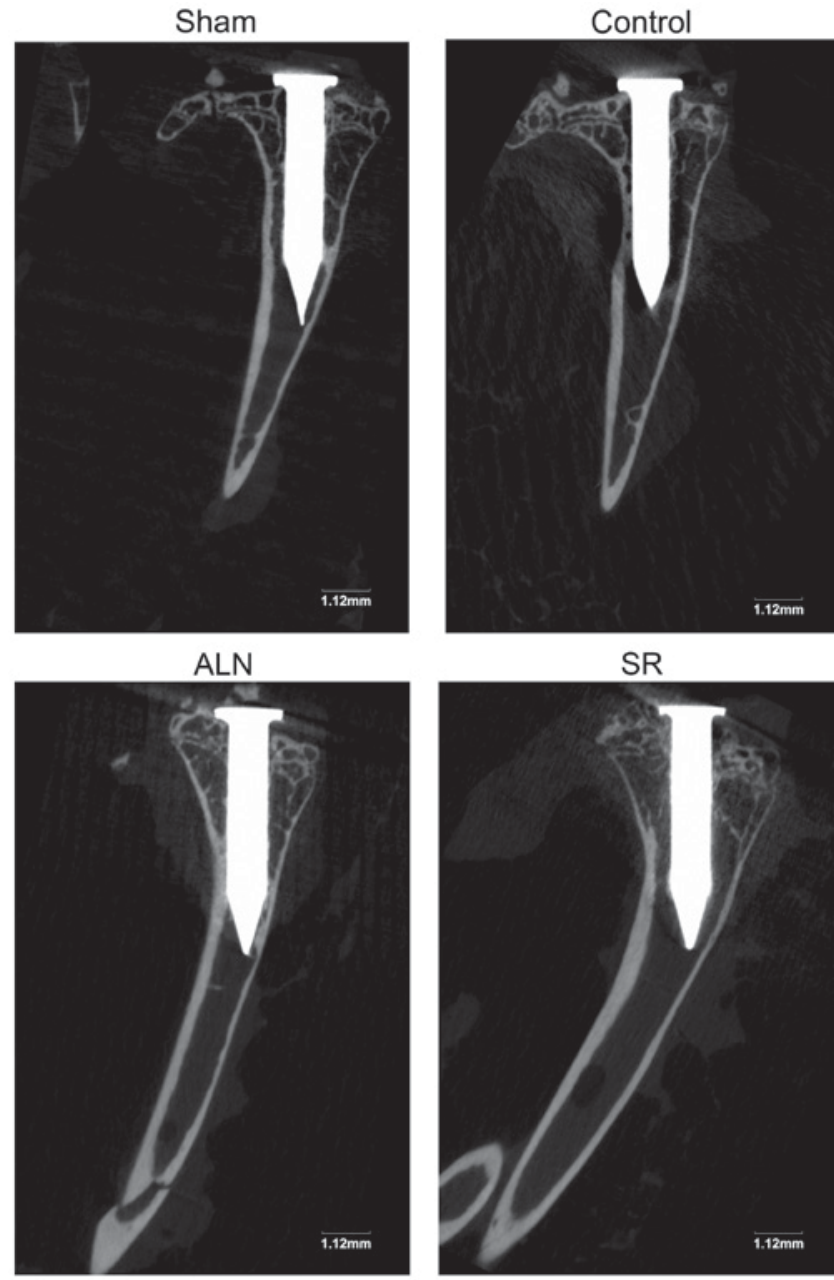

Figure 2. Sagittal-section micro-computed tomography scans of titanium implants. $\mathrm{n}=5$ mice/group. $\mathrm{SR}$, strontium ranelate; ALN, alendronate.

of one-way ANOVA demonstrated that there was a significant difference between the SR group and the ALN group, $\mathrm{P}<0.01$; OCN, $1.11 \pm 0.07$ in the sham group, $1.04 \pm 0.08$ in the control group, $1.37 \pm 0.06$ in the ALN group and 2.04 \pm 0.06 in the SR group; the results of one-way ANOVA demonstrated that there was a significant difference between the SR group and the ALN group, $\mathrm{P}<0.01)$. ALN increased the expression levels of RANKL and OPG simultaneously and decreased the OPG/RANKL ratio; however, SR decreased the RANKL expression level, and increased the OPG expression level and thus the OPG/RANKL ratio (Fig. 5; OPG, $0.41 \pm 0.01$ in the sham group, $0.38 \pm 0.01$ in the control group, $0.62 \pm 0.01$ in the ALN group and $0.88 \pm 0.01$ in the SR group; the results of one-way ANOVA demonstrated that there was a significant difference between the SR group and the ALN group, $\mathrm{P}<0.01$; RANKL, $0.84 \pm 0.02$ in the sham group, $0.84 \pm 0.02$ in the control group, $1.05 \pm 0.04$ in the ALN group and $0.50 \pm 0.01$ in the SR group; the results of one-way ANOVA demonstrated that there was a significant difference between the SR group and the ALN group, $\mathrm{P}<0.01$ ).

\section{Discussion}

Aseptic loosening is an important cause of the failure of total joint prosthesis replacement. As the average age of the population rises, an increasing number of postmenopausal 

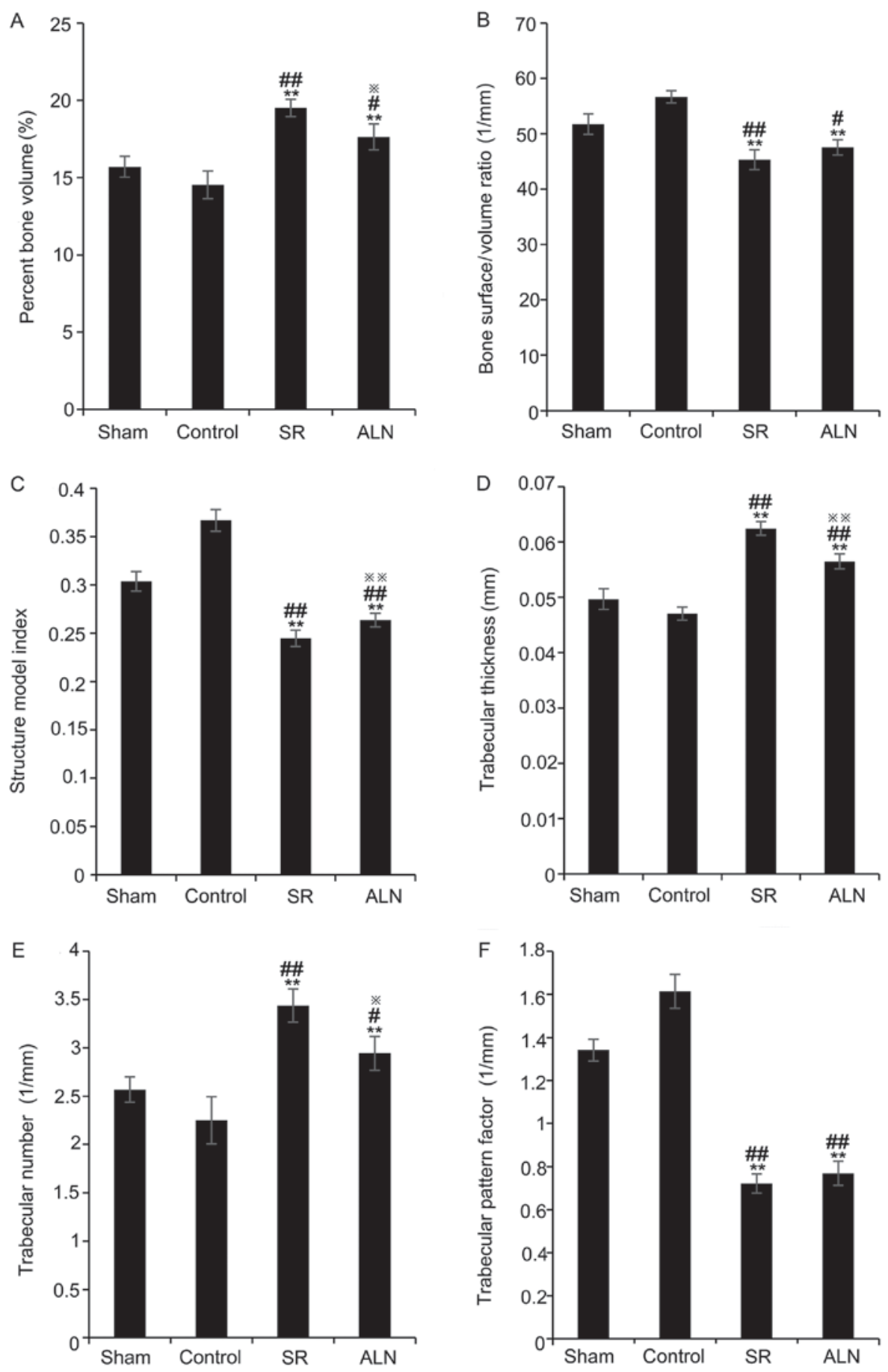

Figure 3. Micro-computed tomography analysis of bone microstructure. (A) Percent bone volume, (B) bone surface/bone volume ratio, (C) structure model index, (D) trabecular thickness, (E) trabecular number and $(\mathrm{F})$ trabecular pattern factor are presented. $\mathrm{n}=5$ mice/group. ${ }^{* *} \mathrm{P}<0.01$ vs. control; ${ }^{*} \mathrm{P}<0.05$, ${ }^{\# \#} \mathrm{P}<0.01$ vs. sham; ${ }^{*} \mathrm{P}<0.05,{ }^{* *} \mathrm{P}<0.01$ vs. SR. SR, strontium ranelate; $\mathrm{ALN}$, alendronate.

patients with osteoporosis require an arthroplasty. An imbalance between bone resorption and bone formation is a common cause of osteoporosis and aseptic loosening. Osteoporosis in patients results in bone mass reduction, which increases the risk of aseptic loosening. The animal experiments in the present study demonstrated that implants fixed in the sham-operated group were more stable compared with in ovariectomized mice. Chen et al (33) demonstrated that SR and ALN improve the bone mass and bone quality of ovariectomized mice and promote bone implant osseointegration. Nevertheless, to the best of our knowledge, there are no studies confirming that SR or ALN prevent aseptic loosening mediated by wear particles in ovariectomized mice. The present results indicate that SR may increase osteoblast activity, and inhibit the release of inflammatory factors, osteoclast activity and differentiation in ovariectomized mice. SR suppresses the aseptic loosening induced by wear particles. ALN may additionally reduce osteolysis around the prosthesis by inhibiting osteoclast activity. Oral administration of SR ( $625 \mathrm{mg} / \mathrm{kg} /$ day) was observed to be more effective compared with ALN $(1 \mathrm{mg} / \mathrm{kg} /$ week $)$ at reducing osteolysis in the ovariectomized mice. 

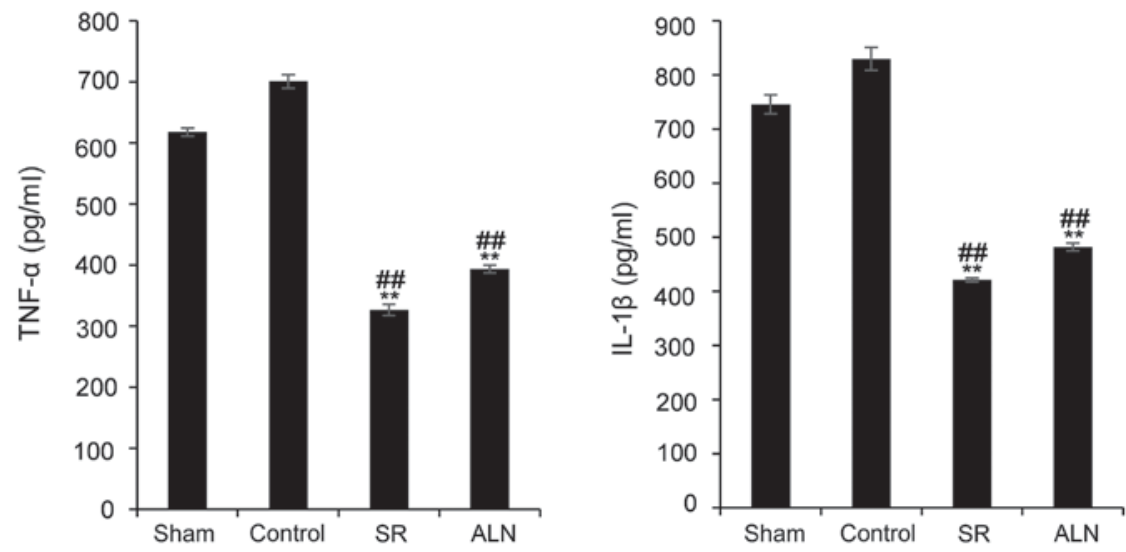

Figure 4. Serum levels of pro-inflammatory cytokines determined by ELISA. Serum concentration of (A) TNF- $\alpha$ and (B) IL-1 $\beta$. $n=5$ mice/group. ${ }^{* *} \mathrm{P}<0.01$ vs. control; ${ }^{\# \#} \mathrm{P}<0.01$ vs. sham. TNF- $\alpha$, tumor necrosis factor- $\alpha$; IL-1 $\beta$, interleukin-1 $\beta ;$ SR, strontium ranelate; ALN, alendronate.
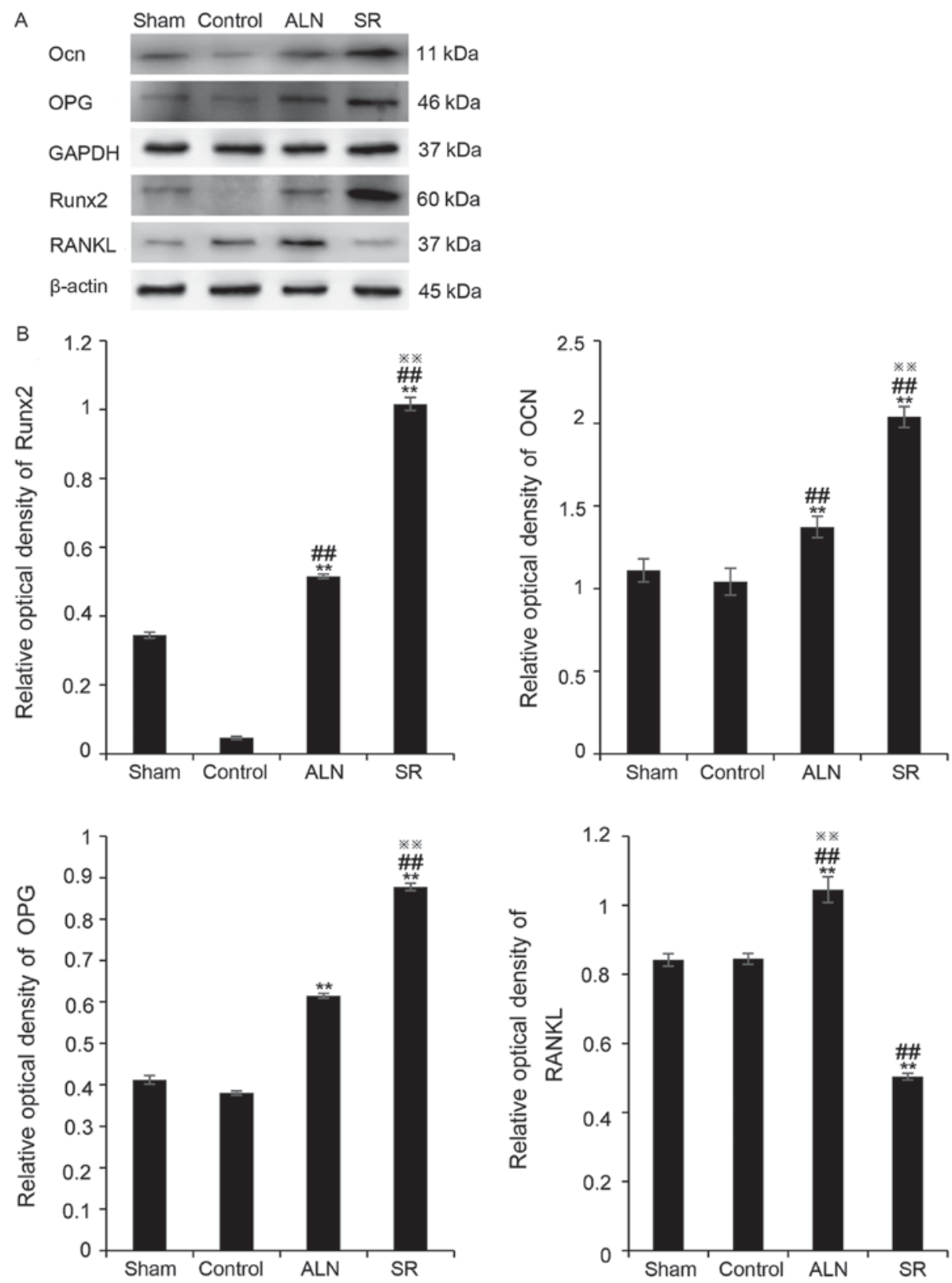

Figure 5. Western blot analysis of proteins in the bone tissue surrounding the implant. (A) Western blot analysis and (B) semi-quantitative analysis of the indicated proteins. The results are presented as the ratio of a target protein to the internal control ( $\beta$-actin). $\mathrm{n}=5$ mice/group. ${ }^{* *} \mathrm{P}<0.01$ vs. control; ${ }^{\# \#} \mathrm{P}<0.01 \mathrm{vs}$. sham; ${ }^{*} \mathrm{P}<0.01$ vs. SR. SR, strontium; ALN, alendronate; OCN, osteocalcin; OPG, osteoprotegerin; Runx2, runt-related transcription factor 2; RANKL, receptor activator of nuclear factor- $\mathrm{kB}$ ligand. 
Compared with the control group, the SR and ALN groups exhibited increased BV/TV, Tb.Th and Tb.N, and lower SMI, BS/BV and Tb.Pf around the tibial prosthesis. The present results are consistent with those of a previous study (33). Previous studies involved young female rats, whereas, 18-month-old mice were the subjects of the present study; this choice may be the reason for the discrepancies in results. The pullout test revealed that compared with the control group, the drug-treated groups required a greater pull force to extract the prosthesis from the tibia, as the prosthesis and surrounding bone tissues were more solid. The SR group required greater force in this assay compared with the ALN group. A previous study demonstrated that the mechanisms of osteoporosis, induced by different factors (including aging and estrogen deficiency), are different (34). SR and ALN may improve bone mass around a prosthesis (35); however, according to the micro-CT data in the present study, the effect of SR is more marked.

Similar to the results of Bonnelye et al (36), the present results suggest that SR and ALN increase the expression of OPG in the tissue. The difference between SR and ALN is that SR inhibited the expression of RANKL and thus increase the OPG/RANKL ratio, in agreement with the data of Karakan et al (25) and Huang et al (7). However, ALN promotes RANKL expression, thus decreasing the OPG/RANKL ratio, as reported by Faverani et al (37). However, a specific study observed that SR has no effect on OPG and RANKL expression in patients with osteoporosis, in contrast to the present results (38). There are numerous potential causes of this discrepancy, such as the difference in the physiological environments between mice and humans. Additionally, different tissues were collected in the different studies. The present study measured the expression levels of OPG and RANKL in the bone tissue around the mouse tibial prosthesis, whereas Stuss et al (38) measured these expression levels in human serum. The effect of SR on RANKL in their experiments was in agreement with the results from the present study. SR and ALN may significantly inhibit the release of proinflammatory factors; the present results demonstrated that the serum expression levels of TNF- $\alpha$ and IL-1 $\beta$ were significantly decreased in the SR and ALN groups compared with the control group, in agreement with previous studies $(7,39,40,41)$. TNF- $\alpha$ is an important factor in the regulation of osteoclast differentiation. Raehtz et al (17) suggested that the TNF- $\alpha$ expression level may affect osteoblast activity and bone formation. The present data revealed that SR may inhibit osteoclast differentiation and reduce bone resorption around the prosthesis by suppressing the release of pro-inflammatory factors in ovariectomized mice. From the detection of osteoblast markers, it was identified that the expression levels of OCN and Runx 2 in the bone tissue around the prostheses were increased in the SR group compared with the control group, in agreement with the results of Bakker et al (42) and Guo et al (43). Treatment with ALN decreased the expression of OCN and Runx 2 compared with treatment with SR, as observed in previous studies conducted by Chen et al (33) and Muise et al (44). In the present study, it was identified that there was a significant difference in the level of runx 2 between the control group and the sham group; this may be due to suppression of osteogenic growth following implantation of the prosthesis. Results of an in vitro study by Kang et al (45), examining the effects of ALN on osteoblasts, are inconsistent with the present results; this discrepancy may be caused by the difference in experimental materials. The study conducted by Kang et al was an in vitro experiment, whereas the present study observed effects in mice. The difference in the experimental results may therefore be due to the interaction of various biological factors in the bodies of the mice. Shimizu et al (46) demonstrated that ALN may inhibit osteoblast activity indirectly by increasing the interaction between osteoclasts and osteoblasts.

Notably, previous studies have reported serious adverse effects of SR, including Stevens-Johnson syndrome and toxic epidermal necrolysis $(47,48)$, although these were not observed in the present study. Topical application of SR is a potential way to minimize these effects (49). Prostheses coated with SR may be able to inhibit aseptic loosening $(50,51)$.

In conclusion, SR and ALN have inhibitory effects on aseptic loosening in ovariectomized mice, and SR may affect osteogenesis and osteoclasts to inhibit aseptic loosening, in agreement with the results of Wornham et al (52). SR has a better inhibitory effect on aseptic loosening compared with ALN and may potentially serve as a treatment of aseptic loosening in patients with osteoporosis. However, certain studies $(53,54)$ reported that SR has serious adverse effects in practical applications, thus raising safety concerns regarding its medicinal use. However, in view of its excellent practical value, it is necessary to examine possible solutions to its disadvantages. Certain studies indicate that topical application of SR is a potential treatment method (43) and another study has demonstrated that a prosthesis with strontium coating has the same inhibitory effect on aseptic loosening (55).

\section{Acknowledgements}

The authors would like to thank Dr Doraemon Z. Gbighe for guidance with experimental techniques.

\section{Funding}

The present study was supported by the National Natural Science Foundation of China (grant no. 81460333/H0606).

\section{Availability of data and materials}

The datasets used or analyzed during the current study are available from the corresponding author on reasonable request.

\section{Authors' contributions}

TG participated in study design, performed the experiments and data analysis, and drafted the manuscript. QJ participated in study design, directed the execution of experiments and revised the article critically for intellectual content. MZ, SS and $\mathrm{XC}$ participated in performing the experiments. HY, SZ and $\mathrm{HG}$ interpreted the results and revised the manuscript. All authors approved the final version of the manuscript.

\section{Ethics approval and consent to participate}

The experimental protocol in the present study was conducted in accordance with the National Institutes of Health Guidelines 
for the Care and Use of Laboratory Animals and was approved by the Ethics Committee of the General Hospital of Ningxia Medical University (Yinchuan, China).

\section{Consent for publication}

Not applicable.

\section{Competing interests}

The authors declare that they have no competing interests.

\section{References}

1. Wang ML, Sharkey PF and Tuan RS: Particle bioreactivity and wear-mediated osteolysis. J Arthroplasty 19: 1028-1038, 2004.

2. Pioletti DP and Kottelat A: The influence of wear particles in the expression of osteoclastogenesis factors by osteoblasts. Biomaterials 25: 5803-5808, 2004.

3. Shao H, Shen J, Wang M, Cui J, Wang Y, Zhu S, Zhang W, Yang $\mathrm{H}, \mathrm{Xu} \mathrm{Y}$ and Geng D: Icariin protects against titanium particle-induced osteolysis and inflammatory response in a mouse calvarial model. Biomaterials 60: 92-99, 2015.

4. Flecher X, Rolland C, Rixrath E, Argenson J, Robert P, Bongrand P, Wendling S and Vitte J: Local and systemic activation of the mononuclear phagocyte system in aseptic loosening of total hip arthroplasty. J Clin Immunol 29: 681-690, 2009.

5. Pajarinen J, Lin T, Nabeshima A, Jämsen E, Lu L, Nathan K, Yao Z and Goodman SB: Mesenchymal stem cells in the aseptic loosening of total joint replacements. J Biomed Mater Res A 105: 1195-1207, 2017.

6. Haleem-Smith H, Argintar E, Bush C, Hampton D, Postma WF, Chen FH, Rimington T, Lamb J and Tuan RS: Biological responses of human mesenchymal stem cells to titanium wear debris particles. J Orthop Res 30: 853-863, 2012.

7. Huang C, Li L, Yu X, Gu Z and Zhang X: The inhibitory effect of strontium-doped calcium polyphosphate particles on cytokines from macrophages and osteoblasts leading to aseptic loosening in vitro. Biomed Mater 9: 025010, 2014

8. Ferreira E, Bortolin RH, Freire-Neto FP, Souza K, Bezerra JF, Ururahy M, Ramos AMO, Himelfarb ST, Abreu BJ, Didone TVN, et al: Zinc supplementation reduces rankl/opg ratio and prevents bone architecture alterations in ovariectomized and type 1 diabetic rats. Nutr Res 40: 48-56, 2017.

9. Szwarc MM, Kommagani R, Jacob AP, Dougall WC, Ittmann MM and Lydon JP: Aberrant activation of the rank signaling receptor induces murine salivary gland tumors. PLoS One 10: e128467, 2015 .

10. Neuerburg C, Wedemeyer C, Goedel J, Schlepper R, Hilken G, Schwindenhammer B, Schilling AF, Jager M and Kauther MD: The role of calcitonin receptor signalling in polyethylene particle-induced osteolysis. Acta Biomater 14: 125-132, 2015.

11. Armas LA and Recker RR: Pathophysiology of osteoporosis: New mechanistic insights. Endocrinol Metab Clin North Am 41 475-486, 2012

12. Riggs BL: The mechanisms of estrogen regulation of bone resorption. J Clin Invest 106: 1203-1204, 2000.

13. Syed F and Khosla S: Mechanisms of sex steroid effects on bone. Biochem Biophys Res Commun 328: 688-696, 2005.

14. Frenkel B, Hong A, Baniwal SK, Coetzee GA, Ohlsson C, Khalid $\mathrm{O}$ and Gabet Y: Regulation of adult bone turnover by sex steroids. J Cell Physiol 224: 305-310, 2010.

15. Gilbert L, He X, Farmer P, Boden S, Kozlowski M, Rubin J and Nanes MS: Inhibition of osteoblast differentiation by tumor necrosis factor-alpha. Endocrinology 141: 3956-3964, 2000.

16. Manolagas SC: Birth and death of bone cells: Basic regulatory mechanisms and implications for the pathogenesis and treatment of osteoporosis. Endocr Rev 21: 115-137, 2000.

17. Raehtz S, Bierhalter H, Schoenherr D, Parameswaran N and McCabe LR: Estrogen deficiency exacerbates type 1 diabetes induced bone $\mathrm{TNF} \alpha$ expression and osteoporosis in female mice. Endocrinology 158: 2086-2101, 2017.

18. Dorr LD, Faugere MC, Mackel AM, Gruen TA, Bognar B and Malluche HH: Structural and cellular assessment of bone quality of proximal femur. Bone 14: 231-242, 1993.
19. Dorr LD, Faugere MC, Mackel AM, Gruen TA, Bognar B and Malluche HH: Structural and cellular assessment of bone quality of proximal femur. Bone 14: 231-242, 1993.

20. Bottai V, Dell'Osso G, Celli F, Bugelli G, Cazzella N, Cei E, Guido G and Giannotti S: Total hip replacement in osteoarthritis: The role of bone metabolism and its complications. Clin Cases Miner Bone Metab 12: 247-250, 2015.

21. Stepan JJ, Alenfeld F, Boivin G, Feyen JH and Lakatos P: Mechanisms of action of antiresorptive therapies of postmenopausal osteoporosis. Endocr Regul 37: 225-238, 2003.

22. Chen BL, Xie DH, Zheng ZM, Lu W, Ning CY, Li YQ, Li FB and Liao WM: Comparison of the effects of alendronate sodium and calcitonin on bone-prosthesis osseointegration in osteoporotic rats. Osteoporos Int 22: 265-270, 2011.

23. O'Hara LJ, Nivbrant B and Rohrl S: Cross-linked polyethylene and bisphosphonate therapy for osteolysis in total hip arthroplasty: A case report. J Orthop Surg (Hong Kong) 12: 114-121, 2004.

24. Reginster JY, Brandi ML, Cannata-Andia J, Cooper C, Cortet B, Feron JM, Genant H, Palacios S, Ringe JD and Rizzoli R: The position of strontium ranelate in today's management of osteoporosis. Osteoporos Int 26: 1667-1671, 2015

25. Karakan NC, Akpinar A, Goze F and Poyraz O: Investigating the effects of systemically administered strontium ranelate on alveolar bone loss histomorphometrically and histopathologically on experimental periodontitis in rats. J Periodontol 88: e24-e31, 2017.

26. Marie PJ: Optimizing bone metabolism in osteoporosis: Insight into the pharmacologic profile of strontium ranelate. Osteoporos Int 14 (Suppl 3): S9-S12, 2003.

27. SunS,GuoH,ZhangJ,YuB,SunKand Jin Q: Adenovirus-mediated expression of bone morphogenetic protein-2 activates titanium particle-induced osteoclastogenesis and this effect occurs in spite of the suppression of tnf-alpha expression by sirna. Int J Mol Med 32: 403-409, 2013.

28. National Research Council (US) Committee for the Update of the Guide for the Care and Use of Laboratory Animals: Guide for the Care and Use of Laboratory Animals. 8th edition. National Academies Press (US), Washington, D.C., 2011.

29. Yang S, Yu H, Gong W, Wu B, Mayton L, Costello R and Wooley PH: Murine model of prosthesis failure for the long-term study of aseptic loosening. J Orthop Res 25: 603-611, 2007.

30. Huang RC, Khan SN, Sandhu HS, Metzl JA, Cammisa FJ, Zheng F, Sama AA and Lane JM: Alendronate inhibits spine fusion in a rat model. Spine (Phila Pa 1976) 30: 2516-2522, 2005

31. Geng T, Sun S, Chen X, Wang B, Guo H, Zhang S and Jin Q: Strontium ranelate reduces the progression of titanium particle-induced osteolysis by increasing the ratio of osteoprotegerin to receptor activator of nuclear factor- $\mathrm{\kappa B}$ ligand in vivo. Mol Med Rep 17: 3829-3836, 2018.

32. Bouxsein ML, Boyd SK, Christiansen BA, Guldberg RE, Jepsen KJ and Müller R: Guidelines for assessment of bone microstructure in rodents using micro-computed tomography. J Bone Miner Res 25: 1468-1486, 2010.

33. Chen B, Li Y, Yang X, Xu H and Xie D: Zoledronic acid enhances bone-implant osseointegration more than alendronate and strontium ranelate in ovariectomized rats. Osteoporos Int 24: 2115-2121, 2013

34. Ucer S, Iyer S, Kim H, Han L, Rutlen C, Allison K, Thostenson JD, de Cabo R, Jilka RL, O'Brien C, et al: The effects of aging and sex steroid deficiency on the murine skeleton are independent and mechanistically distinct. J Bone Miner Res 32: 560-574, 2017.

35. Bouxsein ML, Boyd SK, Christiansen BA, Guldberg RE, Jepsen KJ and Muller R: Guidelines for assessment of bone microstructure in rodents using micro-computed tomography. J Bone Miner Res 25: 1468-1486, 2010.

36. Bonnelye E, Chabadel A, Saltel F and Jurdic P: Dual effect of strontium ranelate: Stimulation of osteoblast differentiation and inhibition of osteoclast formation and resorption in vitro. Bone 42: 129-138, 2008

37. Faverani LP, Polo TO, Ramalho-Ferreira G, Momesso GAC, Hassumi JS, Rossi AC, Freire AR, Prado FB, Luvizuto ER, Gruber R and Okamoto R: Raloxifene but not alendronate can compensate the impaired osseointegration in osteoporotic rats. Clin Oral Invest 22: 255-265, 2018

38. Stuss M, Sewerynek E, Król I, Stępień-Kłos W and Jędrzejczyk S: Assessment of OPG, RANKL, bone turnover markers serum levels and BMD after treatment with strontium ranelate and ibandronate in patients with postmenopausal osteoporosis. Endokrynol Pol 67: 174-184, 2016. 
39. Komrakova M, Weidemann A, Dullin C, Ebert J, Tezval M, Stuermer KM and Sehmisch S: The impact of strontium ranelate on metaphyseal bone healing in ovariectomized rats. Calcif Tissue Int 97: 391-401, 2015.

40. Gur A, Denli A, Cevik R, Nas K, Karakoc M and Sarac AJ: The effects of alendronate and calcitonin on cytokines in postmenopausal osteoporosis: A 6-month randomized and controlled study. Yonsei Med J 44: 99-109, 2003.

41. Liu X, Zhu S, Cui J, Shao H, Zhang W, Yang H, Xu Y, Geng D and Yu L: Strontium ranelate inhibits titanium-particle-induced osteolysis by restraining inflammatory osteoclastogenesis in vivo. Acta Biomater 10: 4912-4918, 2014.

42. Bakker AD, Zandieh-Doulabi B and Klein-Nulend J: Strontium ranelate affects signaling from mechanically-stimulated osteocytes towards osteoclasts and osteoblasts. Bone 53: 112-119, 2013.

43. Guo X, Wei S, Lu M, Shao Z, Lu J, Xia L, Lin K and Zou D: Dose-dependent effects of strontium ranelate on ovariectomy rat bone marrow mesenchymal stem cells and human umbilical vein endothelial cells. Int J Biol Sci 12: 1511-1522, 2016.

44. Muise ES, Podtelezhnikov AA, Pickarski M, Loboda A, Tan Y, Hu G, Thomspon JR and Duong T: Effects of long-term odanacatib treatment on bone gene expression in ovariectomized adult rhesus monkeys: Differentiation from alendronate. J Bone Miner Res 31: 839-851, 2016.

45. Kang AR, Oh YR, Kim HY, Park MJ, Joo BS, Choi WJ, Lee JY, Jung MH, Ji YI and Choi JS: Up-regulation of inhibitors of dna binding/differentiation gene during alendronate-induced osteoblast differentiation. Arch Gynecol Obstet 285: 1331-1338, 2012.

46. Shimizu E, Tamasi J and Partridge NC: Alendronate affects osteoblast functions by crosstalk through ephrinb1-ephb. J Dent Res 91: 268-274, 2012.

47. Rossini M, Adami G, Adami S, Viapiana O and Gatti D: Safety issues and adverse reactions with osteoporosis management. Exp Opin Drug Saf 15: 321-332, 2015.
48. Guo X, Wei S, Lu M, Shao Z, Lu J, Xia L, Lin K and Zou D: Dose-dependent effects of strontium ranelate on ovariectomy rat bone marrow mesenchymal stem cells and human umbilical vein endothelial cells. Int J Biol Sci 12: 1511-1522, 2016.

49. Gu Z, Huang B, Li Y, Tian M, Li L and Yu X: Strontium-doped calcium polyphosphate/ultrahigh molecular weight polyethylene composites: A new class of artificial joint components with enhanced biological efficacy to aseptic loosening. Mater Sci Eng C Mater Biol Appl 61: 526-533, 2016.

50. Tian A, Zhai JJ, Peng Y, Zhang L, Teng MH, Liao J, Sun X and Liang X: Osteoblast response to titanium surfaces coated with strontium ranelate-loaded chitosan film. Int J Oral Maxillofac Implants 29: 1446-1453, 2014.

51. Newman SD, Lotfibakhshaiesh N, O'Donnell M, Walboomers XF, Horwood N, Jansen JA, Amis AA, Cobb JP and Stevens MM: Enhanced osseous implant fixation with strontium-substituted bioactive glass coating. Tissue Eng Part A 20: 1850-1857, 2014

52. Wornham DP, Hajjawi MO, Orriss IR and Arnett TR: Strontium potently inhibits mineralisation in bone-forming primary rat osteoblast cultures and reduces numbers of osteoclasts in mouse marrow cultures. Osteoporos Int 25: 2477-2484, 2014.

53. Rossini M, Adami G, Adami S, Viapiana O and Gatti D: Safety issues and adverse reactions with osteoporosis management. Exp Opin Drug Saf 15: 321-332, 2015.

54. Lee HY, Shen MX, Lim YL, Tay YK, Chan MM, Pang SM, Xiao ZW, Ang SB and Ren EC: Increased risk of strontium ranelate-related sjs/ten is associated with hla. Osteoporos Int 27: 2577-2583, 2016

55. Tian A, Zhai JJ, Peng Y, Zhang L, Teng MH, Liao J, Sun X and Liang X: Osteoblast response to titanium surfaces coated with strontium ranelate-loaded chitosan film. Int J Oral Maxillofac Implants 29: 1446-1453, 2014. 